Cihad Şentürk', PhD, Assistant Professor

Karamanoğlu Mehmetbey University, Faculty of Education

Original scientific paper

Department of Curriculum and Instruction

UDC: 37.015 .1

Gülçin Zeybek², PhD, Assistant Professor

DOI: $10.17810 / 2015.92$

Karamanoğlu Mehmetbey University, Faculty of Education

Department of Curriculum and Instruction

\title{
TEACHING-LEARNING CONCEPTIONS AND PEDAGOGICAL COMPETENCE PERCEPTIONS OF TEACHERS: A CORRELATIONAL RESEARCH ${ }^{3}$
}

\begin{abstract}
The objective of this research is to examine the relationship between teachers' teaching-learning conceptions and pedagogical competence perceptions and to reveal the related findings. The research was designed in the relational survey model. The study group of the research is composed of teachers who work in elementary and secondary public schools in Karaman district of Turkey $(n=223)$. In the research, it was found that there are positive or negative relationships between teachers' teaching-learning conceptions and pedagogical competence perceptions sub-dimensions. In addition, according to regression analysis, it was seen that the model was significant as a whole and teachers' teaching-learning conceptions and pedagogical competence perceptions were significantly associated. It was understood that the teachers' teaching-learning conceptions explained $42 \%$ of their pedagogical competence perceptions. According to the findings of the research, it was observed that teachers mostly had traditional teaching-learning conceptions and there was no significant relationship between their traditional teaching-learning conceptions and their pedagogical competence perceptions except the first dimension. It was found that there was a significantly positive relationship between their teaching-learning conceptions and their pedagogical competence perceptions among teachers who have constructivist teaching-learning conception. According to these findings, teachers' pedagogical competence perception levels decrease as their teaching-learning conceptions move towards the traditional conceptions, and pedagogical competence perception levels increases as their teaching-learning conceptions move towards constructivism. When all these results are taken into consideration, teachers should be educated in accordance with the constructivist teaching-learning conception in line with their contemporary educational philosophies, models and conceptions.
\end{abstract}

Key Words: Teaching-learning conceptions, pedagogical competence perception, teachers, correlational research.

\footnotetext{
${ }^{1}$ corresponding author, cihadsenturk@kmu.edu.tr

2 gulcinzeybek@kmu.edu.tr

3 This study was orally presented at the International Congresses on Education ERPA (June 2018) in İstanbul, Turkey.
} 


\section{Introduction}

Nowadays, there is a serious process of change in teaching and learning which extends from traditional conceptions to constructivism. It is known that this change and transformation in education deeply affects not only in-class processes but also teachers' conceptions. However, many teachers tend to resist changing their teaching practices and intentionally do not accept alternative strategies, methods and techniques. Teachers' perceptions of their own pedagogical competence are considered to be highly effective in their teaching and learning conceptions.

The teaching-learning conceptions represents the ways and methods used by teachers to organize their teaching-learning environments (Chan and Elliot, 2004). According to Chan (2003), the conceptions of teaching-learning are their beliefs about the educational activities they put into practice in the classroom. The teaching-learning conceptions in educational sciences have changed in different periods of history. Schunk (2008) mentions two different opposing teaching-learning conceptions in this process; the traditional teaching-learning conceptions that locatethe teacher at the center and the constructivist teaching-learning conceptions that place the student at the center.

According to the traditional teaching-learning conceptions, the teacher is the only competent authority in the transfer of knowledge and the student is considered as a passive recipient of the information (Brooks and Brooks, 1999). On the other hand, according to the constructivist teaching-learning conception, the teacher's task is not to convey knowledge but to guide the student. In a traditional teaching-learning environment, as teacher-centered activities are organized, students listen and note the teachers. The teacher generally uses the traditional method of expression and the question-answer technique (Gunes, 2014). On the other hand, student-centered activities are organized in a constructivist teaching-learning environment. In such an environment involving rich learning activities, the teacher is not a single and constant source of information. The teacher encourages students to search for information and access alternative sources of information. S/he encourages them when they need, and motivates them for teamwork, and appreciates their achievements and establishes two-way communication with them (Plourde and Alawiye, 2003). Constructivism also recommends that students develop their knowledge based on their prior knowledge, so the students must actively participate in their own learning processes. In constructivist classes, students interact with each other as well as the contents that enable them to be active participants and responsible for learning processes (Şahin and Yilmaz, 2016). In constructivist learning environments, teachers facilitate the learning process by giving students a variety of clues, as well as create learning environments in which students interact with their peers and teachers, and offer them the opportunity to use previous knowledge to create new knowledge. (Jonassen, 1999).

Organization for Economic Co-operation and Development (OECD) focuses on the need to provide high-quality education for all, where teachers and their proven competencies play a vital role (OECD, 2005). This necessity is also supported by the data linking students' performance to teacher qualifications. It has been proven by a number of studies that students' performance levels are higher when teachers' competence is proven (Goldhaber and Brewer, 2000; Darling-Hammond, Berry and Thoreson, 2001; Goldhaber and Anthony 2007; Vandervoort, Amrein-Beardsley and Berliner, 2004). One point that should not be ignored here is the teachers' perceptions of their pedagogical competencies as well as their 
pedagogical competencies. Since teachers' beliefs play an important role in teaching and these beliefs are difficult to change, it is important to know what teachers' beliefs are. According to Richardson (1996), there is a direct link between teachers' beliefs and teaching practices. It has been revealed that teachers with low pedagogical competency perception can avoid activities they think it will force them and their students, and teachers with a high pedagogical competency perception are more likely to develop compelling activities and to help students who have difficulty in the teaching-learning process. Similarly, teachers with traditional teaching-learning conceptions avoid different activities; teachers with constructivist teaching-learning conceptions tend to facilitate different and high-level activities and facilitate the teaching-learning processes (Bas and Senturk, 2017).

\section{The aim and significance of the study}

In the relevant literature, while it is seen that teaching-learning conceptions are conceptualized as traditional and constructivist, these beliefs correspond to the ways teachers prefer in teaching and learning. In the $21^{\text {st }}$ century, teachers are expected to have constructivist conceptions rather than traditional conceptions and to implement appropriate instructional practices in the classroom. At this point, it can be argued that teachers should have a positive perception of pedagogical competence about their capacities in relation to teaching and learning. Teachers who have the knowledge, skills, attitudes and values required by the teaching profession, that is to say, the knowledge of teaching profession, in other words, the teachers with pedagogical competence, are considered to have modern teachinglearning concepts rather than traditional teaching-learning concept. Therefore, it is very important to investigate teachers' teaching-learning conceptions and pedagogical competence perceptions. From this point of view, the aim of this research is to examine the relationship between teachers' teaching-learning conceptions and pedagogical competence perceptions and to reveal the related findings.

In the relevant literature, although there are studies (Liakopoulou, 2011; Suciu and Mata, 2011; Bas and Beyhan, 2013; Bas, 2015; Engin and Dasdemir, 2015; Bas and Senturk, 2017; Bikmaz, 2017; Senturk and Bas, 2018; Yildizli, Saban and Bastug, 2017) in which teachers' teachinglearning conceptions and perceptions of pedagogical competency are analyzed in terms of individual and different variables, (control ideologies, education beliefs, self-efficacy, scientific epistemological beliefs, lifelong learning, teaching motivation, etc.) limited studies in which the relationship between these two phenomena was examined appear. In this respect, it is of great importance to investigate the relationship between teachers' teaching-learning conceptions and pedagogical competence perceptions, as it would contribute tothe literature. Furthermore, it is believed that revealing the relationship between teachers' teaching-learning conceptions and pedagogical competence perceptions will contribute to a better conceptions of teachers' perceptions of these two phenomena in the future as well as contributing to the development of training programs that can be more effective in practice. In this context, the aim of this study was to investigate the relationship between teachers' teaching-learning conceptions and pedagogical competence perceptions.

\section{Methodology}

A correlational survey research model was used in this study. Correlational research has an conceptions in which the direction and strength of the relationship between two or more variables with no influence from any extraneous factor is intended to be found (Creswell, 
2012; Johnson and Christensen, 2010). The main purpose of this type of research is to enlighten the conceptions of important phenomena by revealing the relationships between the variables (Fraenkel and Wallen, 2006). In the present research, the relationship between teachers' teaching-learning conceptions and pedagogical competence perceptions was examined.

\section{Participants}

The participants of the study consisted of teachers $(n=495)$ who were working in public, primary and secondary schools in the central district of Karaman. $45.1 \%$ of these teachers were female $(n=223) ; 54.9 \%(n=272)$ were male. It was determined that $21.6 \%$ of the teachers $(n=107)$ participated in the study had a professional experience between $1-5$ years, $24 \%$ of them $(n=119)$ had $6-10$ years of experience, $7.9 \%(n=39)$ of them had 11-15 years of experience, $18.8 \%(n=93)$ had a professional experience of $16-20$ years and $27.7 \%(n=137)$ of them had professional experience of 21 years and more. Besides, when the institutions that the teachers participated in the research work are examined, it is seen that $28.5 \%(n=141)$ of them were employed in primary and secondary schools and $71.5 \%$ of them $(n=18)$ were employed in secondary schools. In addition, when we look at the education level of teacher, it was found that $4.4 \%(n=22)$ of them had a college degree, $76 \%(n=376)$ of them had a bachelor's degree and 19.6\% ( $n=97)$ of them had a master's degree.

\section{Data Collection Tools}

In this study, Teaching-Learning Conceptions Scale which was developed by Chan and Elliott (2004) and adapted to Turkish by Aypay (2011) as well as Pedagogical Competence Perception Scale developed by Adiguzel (2017) were used in the data collection process. Information about these measurement tools is briefly presented below.

\section{Teaching-Learning Conceptions Scale}

In the study, Teaching-Learning Conceptions Scale which was developed by Chan and Elliott (2004) and adapted into Turkish by Aypay (2011) was used in order to examine teachers' teaching-learning conceptions. The scale consists of a total of 30 items and all items are in 5Likert type ( 1 = I strongly disagree; 2 = I disagree; 3 = I am neutral; 4 = I agree; 5 = I strongly agree). In addition, the scale consisted of two sub-dimensions. These dimensions are (a) Traditional teaching-learning concept (18 items; e.g., "Teaching is simply to explain, present and explain the course subjects."; $a=.83$ ) (b) Constructivist teaching-learning conception (12 items; e.g., "Learning means having plenty of opportunities for students to explore, discuss and express their thoughts"; $\alpha=.88)$. In addition, the results of the confirmatory factor analysis applied to the scale $\left(\mathrm{X}^{2} / \mathrm{sd}=1020.3 / 404 ; \mathrm{GFI}=.93 ; \mathrm{AGFI}=.91 ; \mathrm{RMR}=.050 ; \mathrm{RMSEA}=.067 ; \mathrm{CFI}=.80 ; \mathrm{NFI}=\right.$ $.72 ; \mathrm{RMR}=.050$ and $\mathrm{SRMR}=.065)$ showed that the scale has acceptable values (Aypay, 2011). Therefore, it can be stated that the Teaching-Learning Conceptions Scale is a valid and reliable measurement tool that can be used in determining the teaching-learning conceptions of teachers.

\section{Pedagogical Competence Perception Scale}

In the study, Pedagogical Competence Perception Scale which was developed by Adiguzel (2017) was used as a second scale in order to examine the teachers' pedagogical competence perceptions. The scale consists of a total of 29 items and all items are in 5-Likert types $(1=1$ 
strongly disagree; 2 = I disagree; $3=1$ am neutral; 4 = I agree; 5 = I strongly agree $)$. In addition, the scale consisted of four dimensions. These dimensions are (a) Pre-course Preparation Studies, (4 items; e.g., "In accordance with the characteristics of the course, I make enough pre-course preparation"; $a=76$ ) (b) Course Introduction Activities ( 8 items; eg,. "I stimulate students' curiosity and motivation for learning the subject"; $\alpha=.66$ ), (c) Course Development Activities (10 items, e.g., "I adjust the course speed according to the level of the student"; $a=.86$ ) (d) Course Results Activities (7 items; e.g., "At the end of the course, I check what the students learn, what kind of behaviors they gain", $\alpha=.81$ ). In addition, the KMO coefficient of the scale was 886, and Bartlett's Sphericity value was found as $\chi^{2}=5.866, p<.01$ (Adiguzel, 2017). The confirmatory factor analysis of the scale was not performed by Adiguzel (2017) and was conducted by the researchers in this study. The results obtained from confirmatory factor analysis indicate that the scale has acceptable values $(\chi 2 / d f)=1.73 \quad G F I=0.85, A G F I=0.82$, RMSEA $=0.05, \mathrm{RMS}=0.05, \mathrm{CFI}=0.96, \mathrm{NFI}=0.90$ and $\mathrm{NNFI}=0.94)$.

\section{Data Collection Process}

In order to collect the data for the study, first of all, the necessary permits were obtained from the Directorate of National Education of that province. After obtaining the necessary permits, one of the researchers visited the schools in the sample group and applied the scales to the teachers. In the research, necessary explanations were provided to the teachers in order to apply the scales in a healthy manner. In this context, teachers were informed about the purpose of the research, the nature of the measurement tools and how to fill out them. In addition, teachers were ensured that the answers they provide within the scale would not be used for any purpose other than the scope of the research. Application of the scales to teachers was completed approximately in three weeks. The participants were included in the study on a voluntary basis.

\section{Data Analysis}

In the first part of the study, descriptive statistics such as arithmetic mean, standard deviation and $t$ and $F$ tests were used to determine teachers' conceptions of teaching-learning and their pedagogical competence. In the next stage, the relationship between teachers' teachinglearning conceptions and pedagogical competence perceptions was investigated through the Pearson Product Moment Correlation technique (Cohen, West and Aiken, 2014). In the next phase of the study, multiple regression analysis was conducted to examine the effect of teachers' teaching-learning conceptions on their pedagogical competence perceptions (Gelman and Hill, 2006). In this study, Mahalanobis distance values and skewness and kurtosis values were checked before the regression analysis (Buyukozturk, 2010). The data determined to violate the normality assumption were excluded from the analysis. As a result of the performed analysis, it was determined that there is no value preventing the linearity and normality assumptions in the data and thus, it was found that the linearity and normality hypotheses were met. Besides, whether the data set meets the linearity assumption is controlled by examining the cumulative fallout matrix graph of dependent and independent variables. The obtained results show that the scatter diagrams generated for the standardized residual values and standardized dependent values reveal a linear relationship. At the same time, it was examined whether there was autocorrelation among the variables included in the regression analysis (Tabachnick and Fidell, 2007) and it was decided that there was no autocorrelation considering Durbin-Watson value ( $D-W=2.09$ ). In addition, the data set was examined in terms of multiple linearity hypotheses and it was found that there was no 
multicollinearity between the independent variables. In this study, the variance inflation factor (VIF) and the condition index $(\mathrm{Cl})$ were investigated, and the variance inflation factor values of the variables were found as 0.00-1.99 and the condition index values were found as 1.00-16.20. If the variance inflation factor (VIF) value is equal to or greater than 10, and the condition index $(\mathrm{Cl})$ value is equal to or greater than 30 , it is stated that there is multicollinearity (Buyukozturk, Cokluk and Koklu, 2011; Gelman and Hill, 2006; Tabachnick and Fidell, 2007). In this context, the obtained values showed that there is no multicollinearity problem between the independent variables. After all these examinations, it was seen that the data set was appropriate for multiple regression analysis and relevant analyses were performed.

\section{Results}

In this part of the study, research findings are given. The findings of the study were discussed under three headings, and the findings related to descriptive analyses are presented under the first headings, the findings related to correlation analyses are given under the second headings and the findings related to regression analyses are given under the last headings.

\section{Results of Descriptive Analyses}

In this part of the study, findings related to descriptive analyses including values such as arithmetic mean and standard deviation are given. In this sense, descriptive statistics for the variables are presented in Table 1.

Table 1: Descriptive Statistics of Research Variables

\begin{tabular}{lccccc}
\hline Variables & M & SD & Min. Max. & SE \\
\hline Teachers' Teaching-Learning Conceptions & & & & & \\
$\begin{array}{l}\text { a. Traditional conception to teaching-learning } \\
\text { b. Constructivist teaching-learning conception }\end{array}$ & 2.53 & 0.471 & 1.50 & 5.00 & 0.021 \\
\hline Teachers' Perceptions of Pedagogical Competence & 0.656 & 1.17 & 4.72 & 0.029 \\
$\begin{array}{l}\text { a. Competence perceptions of pre-course preparatory studies } \\
\text { b. Competence perceptions of course introduction activities }\end{array}$ & 3.01 & 0.540 & 1.00 & 5.00 & 0.024 \\
$\begin{array}{l}\text { c. Competence perceptions of course development activities } \\
\text { d. Competence perceptions of course result activities }\end{array}$ & 3.12 & 0.488 & 2.40 & 4.50 & 0.021
\end{tabular}

According to the descriptive statistics presented in Table 1, it was observed that the participant teachers had a low-level constructivist teaching-learning conception $(M=2.52$, SD $=0.656)$ and a high-level traditional teaching-learning conception $(M=4.33, \mathrm{SD}=0.471)$. In addition, the participants had high-level competency perceptions of pre-course preparatory studies $(M=4.00, S D=0.470)$, had medium level competency perceptions of course introductory activities $(M=3.01, S D=0.540)$, had medium level competency perceptions of course development activities $(M=3.12, S D=0.488)$ and had medium level competency perceptions of course result activities $(M=3.09, S D=0.518)$. 
In the study, teachers' teaching-learning conceptions and pedagogical competence perceptions were also compared in terms of some variables. First of all, the normality test was applied to determine whether the data showed normal distribution and it was determined that the data did not have a normal distribution (K-S Teaching-learning conceptions $=0.113, \mathrm{p}<0.05 ; \mathrm{K}-\mathrm{S}$ Pedagogical Competence Perceptions $=0.088, \mathrm{p}<0.05)$. In this context, non-parametric tests were determined to be used in the analysis of the data.

Regarding teachers' teaching-learning conceptions, while there was no statistically significant difference among teachers by gender variable in terms of traditional teaching-learning conception $\left(U_{[493]}=27246,500, p>0.05\right)$; a statistically significant difference was found in terms of constructivist teaching-learning conception $\left(U_{[493]}=26924,000, p<0.05\right)$. As a result of the significant difference found in terms of constructivist teaching-learning conception by the gender variable, mean scores were calculated and it was seen that male teachers had higher scores than female teachers. In this respect, it can be said that male teachers have higher constructivist teaching-learning conceptions than female teachers.

Regarding the teacher's perceptions of pedagogical competence, there was no significant difference found by gender variable in terms of competence perceptions of pre-course preparatory studies $\left(U_{[493]}=28681,000, p>0.05\right)$, of course introduction activities competence perceptions $\left(U_{[493]}=28759,000, p>0.05\right)$ and of competence perceptions of the course development activities $\left(\mathrm{U}_{[493]}=29744,500, \mathrm{p}>0.05\right)$. However, a significant difference was found in terms of competence perceptions of course result activities $\left(U_{[493]}=52146,000, p\right.$ $<0.05)$. As a result of the significant difference found in this aspect, the mean scores were reviewed and it was observed that male teachers had higher scores than female teachers. In light of these findings, it can be said that male teachers have higher competency perceptions of course result activities than the female teachers.

According to the professional experience variable, a significant difference was found in terms of traditional teaching-learning conception related to teachers' teaching-learning conceptions $\left(x^{2}=11,634, p<.05\right)$ and in terms of constructivist teaching-learning conception $\left(x^{2}=10,077, p\right.$ $<.05)$. The Mann Whitney $U$ test, which is preferred in paired comparisons, was used in order to determine from which groups the significant difference obtained from the Kruskal Wallis test comes. As a result of the analysis, it was determined that there was a significant difference between teachers having professional experience of 1-5 years and teachers having professional experience of 21 years and more. According to the average scores, it was found that teachers with professional experience of 1-5 years and 6-10 years exhibited a more constructivist teaching-learning conception than the teachers with professional experience of 21 years and above.

According to the professional experience variable, no significant difference was found regarding teachers' pedagogical competency perceptions, in terms of pre-course preparatory studies competence perceptions $x^{2}=7,403, p>.05$ ), in terms of course development activities competence perceptions $\left(x^{2}=8,839, p>.05\right)$ and in terms of course result activities competence perceptions, $\left(x^{2}=4,643, p>.05\right)$. However, a significant difference was found in terms of course introduction activities competence perceptions $\left(x^{2}=32,661, p<0.05\right)$. In addition, the Mann Whitney $U$ test, which is preferred in paired comparisons, was used in order to determine from which groups this significant difference obtained from the Kruskal Wallis test comes from. As a result of the analysis, it was found out that the teachers having vocational experience of 16-20 years and 21 years and above had higher competency 
perceptions of course introduction activities compared to teachers with vocational experience of $1-5$ years and 6-10 years.

Regarding teachers' traditional teaching-learning conceptions, a statistically significant difference was found in terms of traditional teaching-learning conceptions by the school type worked $\left(U_{[493]}=21539,500, p<0.05\right)$ and in terms of constructivist teaching-learning conceptions $\left(U_{[493]}=21018,000, p<0.05\right)$. According to the variable of served school type (primary or secondary education), as a result of the significant difference found in terms of traditional and constructivist teaching-learning conceptions, the mean scores were taken into consideration and it was observed that the teachers working in primary schools had higher scores than the teachers working in secondary schools. In this respect, it can be said that the teachers working in primary schools have a higher level of constructivist teaching-learning conception than the teachers working in secondary schools.

There was no significant difference found regarding teachers' pedagogical competence perceptions by the school type variable in terms of pre-course preparatory studies $\left(\mathrm{U}_{[493]}=\right.$ 23547.500, $p>0.05$ ), course development activities competence perceptions $\left(U_{[493]}=\right.$ 24631.500, $p>0.05)$ and the course results competence perceptions $\left(U_{[493]}=22527.000\right.$, $\mathrm{p}<0.05)$. However, a significant difference was observed in terms of course introduction activities competence perceptions $\left(U_{[493]}=19198,500, p<0.05\right)$. As a result of the significant difference in this aspect, the mean scores were examined and it was observed that the teachers working in primary schools had higher scores than the teachers working in secondary schools. In light of these findings, it can be said that the teachers who work in primary schools have higher level of competency perceptions of course introduction activities than the teachers working in secondary schools.

A significant difference was found regarding teachers' teaching-learning conceptions by the educational status variable in terms of traditional teaching-learning conception $\left(x^{2}=23.371, p\right.$ $<.05)$ and constructivist teaching-learning conception $\left(x^{2}=21.964, p<.05\right)$. The Mann Whitney $U$ test, which is preferred in paired comparisons, was used in order to determine from which groups the significant difference obtained from the Kruskal Wallis test comes. As a result of the analysis, it was determined that there is a significant difference between the teachers who have graduate education level and the teachers who have undergraduate education and college degree. When the average scores are examined, it was concluded that the teachers who have a graduate level of education have a higher level of constructivist teaching-learning conception than the teachers who have undergraduate and college degree.

Regarding teachers' pedagogical competence perceptions by the educational status, no significant difference was found in terms of the pre-course preparatory studies $\left(x^{2}=0.480\right.$, $p>.05)$ and of the course results competence studies, $\left(x^{2}=3.428, p>.05\right)$. However, a significant difference was found in terms of the course introduction activities competence perceptions $\left(x^{2}=6.799, p<0.05\right)$ and of the course development activities competence perceptions $\left(x^{2}=\right.$ $15.017, p<0.05)$. The Mann Whitney $U$ test, which is preferred in paired comparisons, was used in order to determine from which groups the significant difference obtained from the Kruskal Wallis test comes. As a result of the analysis, it was determined that there was a significant difference between the teachers who had a graduate education level and the teachers who had undergraduate education and college degree. When the average scores are examined, it can be stated that the teachers who have a master's degree in education have a higher level 
of course introduction activities and course development activities competence perceptions than the teachers who have a bachelor's degree and a college degree.

\section{Findings Regarding Correlation Analysis}

In the research, Pearson moment product correlation analysis was conducted in the process of revealing the relationship between teachers' teaching-learning conceptions and pedagogical competency perceptions.

Table 2: Correlation Matrix Between Research Variables

\begin{tabular}{|c|c|c|c|c|c|c|}
\hline Variables & 1 & 2 & 3 & 4 & 5 & 6 \\
\hline \multicolumn{7}{|l|}{ Teachers' Teaching-Learning Conceptions } \\
\hline a. Traditional conception to teaching-learning & - & $\begin{array}{c}- \\
.191 * *\end{array}$ & $.536 * *$ & .075 & 274 & .083 \\
\hline b. Constructivist teaching-learning conception & & - & $.293^{* *}$ & $.845^{* *}$ & $.789^{* *}$ & $.782^{* *}$ \\
\hline \multicolumn{7}{|l|}{ Teachers' Perceptions of Pedagogical Competence } \\
\hline $\begin{array}{l}\text { a. Pre-course preparatory studies competence } \\
\text { perceptions }\end{array}$ & & & - & $.381^{* *}$ & $.370^{* *}$ & $.277^{* *}$ \\
\hline $\begin{array}{l}\text { b. Course introduction activities competence } \\
\text { perceptions }\end{array}$ & & & & - & $.675^{* *}$ & $.578^{* *}$ \\
\hline $\begin{array}{l}\text { c. Course development activities competence } \\
\text { perceptions }\end{array}$ & & & & & - & $.641^{* *}$ \\
\hline d. Course result activities competence perceptions & & & & & & - \\
\hline
\end{tabular}

According to the findings of the study, it was seen that there was a positive significant relationship between teachers' traditional teaching-learning conceptions and pre-course preparatory studies competence perceptions $(r=.536, p<.01)$; and it was also determined that there were no significant relationship between teachers' traditional teaching-learning conceptions and course introduction competence perceptions $(r=.075, p>.01)$, as well as between course development activities competence perceptions $(r=.274, p>.01)$ and course result activities competence perceptions $(r=.083, p>.01)$.

A significant positive relationship was observed between teachers' constructivist teachinglearning conceptions and pre-course preparatory studies competence perceptions $(r=.293$, $\mathrm{p}<.01)$, and between course introduction competence perceptions $(r=.845, p<.01)$, and course development activities competence perceptions $(r=.789, p<.01)$ and course result activities competence perceptions $(r=.782, p<.01)$. In addition to this, it was found that there was a significant negative relationship between teachers' traditional teaching-learning conceptions and constructivist teaching-learning conceptions $(r=-.191, p<.01)$.

\section{Findings Regarding Regression Analysis}

In the study, linear regression analysis was employed for teachers' perceptions of teachinglearning and pedagogical competence perceptions. The results of the linear regression analysis performed are presented in Table 3. 
Table 3: Prediction Level of Teachers' Teaching-Learning Perceptions of the Pedagogical Competence Perceptions

\begin{tabular}{lccccc}
\hline Predictor Variable & B & Std. Error & $\boldsymbol{\beta}$ & $\mathbf{t}$ & $\mathbf{p}$ \\
\hline (Constant) & 25.792 & 4.739 & & 5.442 & $.000^{* *}$ \\
Teaching-Learning Perceptions & 0.559 & 0.030 & .648 & 18.882 & $.000^{* *}$ \\
\hline$R=.648, R^{2}=.420, F_{[1-493]}=356.549, * * p<0.01$ & & & &
\end{tabular}

Table 3 shows the findings for the prediction level of teachers' teaching-learning perceptions of pedagogical competence perceptions. According to the regression analysis, it was seen that the model was significant $\left(F_{[1-493]}=356.549, \mathrm{p}<0.01\right)$ as a whole and teachers' teachinglearning conceptions and pedagogical competence perceptions were significantly associated $\left(R=.648, R^{2}=.420\right)$. It is understood that teachers' teaching-learning conceptions explain $42 \%$ of their pedagogical competence perceptions. This result shows that the total of teachers 'teaching-learning conceptions is a strong predictor of teachers' perception of pedagogical competence. Table 4 presents the findings of the multiple linear regression analysis related to the pre-course preparatory studies competence perceptions which is one of the sub-dimensions of teaching-learning conceptions of the teachers and of the pedagogical competency perceptions.

Table 4: Prediction Level of Teachers' Teaching-Learning Conceptions of the Pre-course Preparatory Studies Competence Perceptions

\begin{tabular}{lcccc}
\hline Predictor Variable & B & Std. Error & $\boldsymbol{\beta}$ & $\mathbf{t}$ \\
\hline (Constant) & .606 & .171 & & $3.549^{* *}$ \\
a. Traditional teaching-learning conception & .613 & .034 & .615 & $18.048^{* *}$ \\
b. Constructivist teaching-learning conception & .294 & .024 & .411 & $12.051^{* *}$ \\
\hline$R=.671, R^{2}=.450, F_{[2-492]}=201.245, * * p<0.01$ & & & &
\end{tabular}

Table 4 shows the findings regarding the prediction level of teachers' teaching-learning conception of pre-course preparatory studies competency perceptions, which is the first of the sub-dimensions of pedagogical competence perceptions. According to the analysis, it was found that the model as a whole was significant $\left(F_{[2-492]}=201.245, p<0.01\right)$ and the traditional teaching-learning conception of teachers $(B=.615)$, and pre-course preparatory studies were the most important sub-dimensions explaining the competency perceptions. Similarly, it was found that the other sub-dimension that predicts teachers' pre-course preparatory competence perceptions was the constructivist teaching-learning conception $(B=.411)$. Traditional and constructivist teaching-learning conceptions were found to be satisfactorily significant. It was seen that the teaching-learning conceptions of teachers explained $45 \%$ of the total variance of pre-course preparatory studies competence perceptions $\left(R=.671, R^{2}=\right.$ .450). These findings reveal that pre-course preparatory studies competence perceptions of the teachers are explained at an intermediate level by traditional and constructivist teachinglearning conceptions. Table 5 presents the findings regarding multiple linear regression analysis of the teacher's teaching-learning conceptions sub-dimensions and course introduction activities competence perceptions. 
Table 5: Prediction Level of Teachers' Teaching-Learning Conceptions of the Course Introduction Activities Competence Perceptions

\begin{tabular}{lcccc}
\hline Predictor Variable & B & Std. Error & $\beta$ & t \\
\hline (Constant) & -.064 & .126 & & -.509 \\
a. Traditional teaching-learning conception & .282 & .025 & .246 & $11.208^{* *}$ \\
b. Constructivist teaching-learning conception & .734 & .018 & .892 & $40.632^{* *}$ \\
\hline
\end{tabular}

$R=.878, R^{2}=.772, F_{[2-492]}=831.612, * * p<0.01$

Table 5 shows the findings regarding the prediction level of teachers' teaching-learning conception of the course introduction activities competence perceptions as the second subdimension of pedagogical competence perceptions. According to the analysis, it was found that the model is significant as a whole $\left(F_{[2-492]}=831.612, \mathrm{p}<0.01\right)$ and teachers' constructivist teaching-learning concept $(\theta=.892)$, was the most important sub-dimension explaining the course introduction activities competence perception. Similarly, it was found that the other sub-dimension which predicts the teachers' course introduction activities competence perceptions is the traditional teaching-learning conception $(B=.246)$. Conventional and constructivist teaching-learning conceptions were found to be satisfactorily significant. It was seen that the teaching-learning conceptions of the teachers explained $77 \%$ of the course introduction activities competence perceptions in the total variance $\left(R=.878, R^{2}=.772\right)$. These findings indicate that the course introduction activities competence perceptions of the teachers are strongly explained by traditional and constructivist teaching-learning conceptions. Table 6 presents the findings of the multiple linear regression analysis of the course development activities competence perception as another sub-dimension of the teachers' teaching-learning conceptions and the pedagogical competence perceptions.

Table 6: Prediction Level of Teachers' Learning-Learning Conceptions of the Course Development Activities Competence Perceptions

\begin{tabular}{lcccc}
\hline Predictor Variable & B & Std. Error & $\beta$ & t \\
\hline (Constant) & -.501 & .104 & & $-4.804^{* *}$ \\
a. Traditional teaching-learning conception & .457 & .021 & .441 & $22.060^{* *}$ \\
b. Constructivist teaching-learning conception & .650 & .015 & .873 & $43.654^{* *}$ \\
\hline$R=.900, R^{2}=.810, F_{[2-492]}=1050.403,{ }^{* *} p<0.01$ & &
\end{tabular}

Table 6 shows the findings regarding the prediction level of the teachers' teaching-learning conception of the course development activities competence perceptions as the third subdimension of pedagogical competence perceptions. According to the analysis, it was understood that the model is significant as a whole $\left(F_{[2-492]}=1050.403, p<0.01\right)$ and teachers' constructivist teaching-learning conception $(6=.873)$ is the most important sub-dimension which explains the course development activities competence perceptions. Similarly, it was understood that the other sub-dimension that predicts teachers' course development activities competence perceptions was the traditional teaching-learning conception $(b=.441)$. Conventional and constructivist teaching-learning conceptions were found to be satisfactorily significant. It was seen that the teaching-learning conceptions of the teachers explained the $81 \%$ of the course development activities competence perceptions in the total variance $(R=$ $\left..900, R^{2}=.810\right)$. This finding reveals that the course development activities competence 
perceptions of teachers are explained more strongly by traditional and constructivist teaching-learning conceptions. Table 7 presents the findings of multiple linear regression analysis of the course result in activities competence perceptions as another sub-dimension of the teachers' teaching-learning conceptions and pedagogical competence perceptions.

Table 7: Prediction Level of Teachers' Teaching-Learning Conceptions of the Course Result Activities Competence Perceptions.

\begin{tabular}{lcccc}
\hline Predictor Variable & B & Std. Error & $\boldsymbol{\beta}$ & $\mathbf{t}$ \\
\hline (Constant) & .293 & .147 & & $2.002^{*}$ \\
a. Traditional teaching-learning conception & .265 & .029 & .241 & $9.101^{* *}$ \\
b. Constructivist teaching-learning conception & .653 & .021 & .828 & $31.223^{* *}$ \\
\hline$R=.817, R^{2}=.667, F_{[2-492]}=492.523,{ }^{*} p<0.05, * * p<0.01$ & & &
\end{tabular}

Table 7 shows the findings related to the prediction level of the course result in activities competence perceptions as the last sub-dimension of pedagogical competence perceptions of teachers' teaching-learning conceptions. According to the analysis, it was understood that the model is significant as a whole $\left(F_{[2-492]}=492.523, \mathrm{p}<0.01\right)$ and teachers' constructivist teaching-learning conception $(\theta=.828)$, is the most important sub-dimension which explains the course development activities competence perceptions. Similarly, it was understood that the other sub-dimension that predicts teachers' course development activities competence perceptions was the traditional teaching-learning conception $(6=.241)$. Traditional and constructivist teaching-learning conceptions were found to be satisfactorily significant. It was seen that the teaching-learning conceptions of the teachers explained $66 \%$ of the total variance of the course development activities competence perceptions $\left(R=.817, R^{2}=.667\right)$. This finding reveals that teachers' course development activities competence perceptions are well explained by traditional and constructivist teaching-learning conceptions.

\section{Discussion, Conclusion and Recommendations}

The objective of this research was to examine the relationship between teachers' conceptions of teaching-learning and pedagogical competence perceptions and to reveal the related findings. The findings of the study were discussed in three sections; the first part follows teachers' teaching-learning conceptions and the descriptive analyses about the pedagogical competence perceptions, in the second part the correlation analysis between the learning conceptions and pedagogical competence perceptions were presented, and in the final section, the findings regarding the regression analysis were given. According to the results of the descriptive analyses conducted in the first part, it was observed that the participants had a low-level constructivist teaching-learning conception and a high-level traditional teachinglearning conception. In addition, considering the pedagogical competence perceptions of the teachers participating in the research, it was understood that they have high-level pre-course preparation competency perceptions, medium level course introduction competence perceptions, medium-level course development activities competence perceptions and medium-level course result activities competence perceptions.

In the second part of the study, a correlation analysis was conducted for the relationship between teachers' teaching-learning conceptions and pedagogical competence perceptions, and a relationship was found between these two phenomena. According to this result, it was 
seen that while there are positively significant relationships between teachers' traditional teaching-learning conceptions and pre-course preparatory studies competence perceptions; there was no significant relationship between the traditional teaching-learning conceptions of the teachers and the course introduction activities competence perceptions as well as between the course development activities competence perceptions and course result activities competence perceptions. According to this, there is no relation between the pedagogical competence perceptions of teachers embracing traditional teaching-learning conception in other aspects except the pedagogical competence perceptions in the precourse preparatory studies. The philosophical foundations of traditional teaching-learning conception are based on perennialist and fundamentalist educational conceptions (Phillips, 2003). Therefore, teachers who embrace a traditional teaching-learning conception in Turkey and in many countries of the world where the education programs are designed with the philosophies of modern education curriculum are not expected to have a high-level of pedagogical competence perceptions. Besides, teachers with a traditional teaching-learning conception do not allow teaching-learning process to be guided by the students. This task is performed only by the teacher (Brooks and Brooks, 1999; Gagnon and Collay, 2001; Wildman, 2008). Teachers who embrace a traditional teaching-learning conception, direct the class only themselves, take decisions on their own, do not share power and authority with anyone and shape the teaching-learning process themselves (Bas, 2014). In this respect, it is thought that the existence of a positively significant relationship between traditional teaching-learning conceptions and pre-course preparatory studies competency perceptions is due to the teachers required to plan the teaching-learning process in advance and make course preparatory studies.

It was found that there were positively significant relationships between teachers' constructivist teaching-learning conceptions and pedagogical competence perceptions in all aspects. This finding was actually the expected and predicted result. Because the teacher who has a pedagogical competence understands how the student structures the knowledge, how $\mathrm{s} /$ he gains the knowledge and skills, how s/he develops an attitude towards learning. Pedagogical competence requires the knowledge of developmental, social and cognitive learning theories and how to apply them to students in the classroom (Mishra and Koehler, 2006; Koehler and Mishra, 2009). Teachers who embrace constructivist teaching-learning conceptions are expected to provide experiences that supports the configuration process of the information, to support the multiple perspectives, establish a relationship between real life and learning, to provide active engagement of the learner in the learning process, to encourage learning in different ways, to provide interactive learning, to support the autonomy of learners, by ensuring the learner to take the responsibility of learning, to provide spectacular environments for learners in order to have rich learning experiences and are expected to guide them through the process of creating meaning (Djamarah, 2005; Gagnon and Collay, 2001). As can be understood from these statements, there is a connection between the pedagogical competencies of teachers and their constructivist teaching-learning conceptions. In this respect, the research finding that the positively significant relationship between constructivist teaching-learning conceptions and pedagogical competence perceptions of teachers is a result which coincides with the existing literature. In addition, the regression analysis indicated that teachers' teaching-learning conceptions significantly predict their pedagogical competence perceptions.

Today, as in every field in the world, there is a rapid change in the field of education, and it is seen that there are serious changes and transformations that extends from traditional to 
constructivism in teaching and learning (Leung, 2008). It is considered that this change and transformation not only affect in-class processes but also deeply affects the conceptions of teachers. As a result of these changes and transformations in the world, teacher competencies have also changed and been transformed (Ministry of National Education, Republic of Turkey [MEB], 2017; OECD, 2017). Today, there is a need for individuals who take responsibility, discuss, think critically, analytically and reflectively, who learned how to learn, is information technology and media literate, is entrepreneurial, and develop innovative ideas (OECD 2018). For this reason, there is a need for teachers who have a constructivist teachinglearning conception and who have high pedagogical competence perceptions. In this respect, it is very important to train teachers who have the qualities which are required today and will be required in the future in the faculties of education.

\section{References}

Aslan, S. (2018). Investigating the relation between educational philosophies adopted by prospective teachers and their teaching-learning conceptions, Pegem Journal of Education and Instruction, 8(2), 307-326.

Aypay, A. (2011). The adaptation of the teaching-learning conceptions questionnaire and its relationships with epistemological beliefs, Educational Sciences: Theory \& Practice, 11(1), 7-29.

Bas, G. (2015). Correlation between teachers' philosophy of education beliefs and their teaching-learning conceptions, Education and Science, 40(182), 111-126.

Bas. G., \& Beyhan, O. (2013). Correlation between pre-service teachers' teaching-learning conceptions and their student control ideologies, Hacettepe University Journal of Education, Special edition (1), 14-26.

Bas. G., \& Senturk, C. (2017). Teaching-learning conceptions and sense of efficacy: A research on prospective teachers. Paper presented at the meeting of the $26^{\text {st }}$ International Conference on Educational Sciences, Antalya.

Bikmaz, F. (2017). An investigation of teaching-learning conceptions and scientific epistemological beliefs of prospective teachers: A longitudinal study, Education and Science, 42(189), 183-196.

Brooks, J. G., \& Brooks, M. G. (1999). In search of understanding: The case for constructivist classrooms. Alexandria, Virginia USA: Association for Supervision and Curriculum Development.

Buyukozturk, S., Cokluk, O., \& Koklu, N. (2011). Sosyal bilimler icin istatistik [Statistics for social sciences] ( $7^{\text {th }}$ ed.). Ankara: Pegem Akademi Publishing.

Buyukozturk, S. (2010). Sosyal bilimler icin veri analizi el kitabi [Data analysis handbook for social sciences] ( $12^{\text {th }}$ ed.). Ankara: Pegem Akademi Publishing.

Chan, K. W. (2003). Hong Kong teacher education students' epistemological beliefs and approaches to learning, Research in Education, 69, 36-50.

Chan, K. W. \& Elliott, R. G. (2004). Relational analysis of personal epistemology and conceptions about teaching and learning, Teaching and Teacher Education, 20(8), 817831.

Cohen, P., West, S. G., \& Aiken, L. S. (2014). Applied multiple regression/correlation analysis for the behavioral sciences. Hove, East Sussex: Psychology Press.

Creswell, J. W. (2012). Educational research: Planning, conducting, and evaluating quantitative and qualitative research ( $4^{\text {th }}$ ed.). New York: Pearson. 
Darling-Hammond, L., Berry, B., \& Thoreson, A. (2001) Does teacher certification matter? Evaluating the evidence, Educational Evaluation and Policy Analysis, 23(1), 57-77.

Djamarah, S. B. (2005). Teachers and learners in educational interaction psychological: A theoretical approach. Jakarta: Rineka Cipta.

Engin, G. \& Dasdemir, I. (2015). Evaluation of primary school teachers' teaching-learning conceptions with regards to different variables, The Journal of Academic Social Science Studies, 33, 425-432.

Fraenkel, J. R., \& Wallen, N. E. (2006). How to design and evaluate research in education $\left(6^{\text {th }}\right.$ ed.). New York: McGraw-Hill.

Gagnon, G. W., \& Collay, M. (2001). Designing for learning: Six elements in constructivist classrooms. Thousand Oaks, CA: Corwin Press, Inc.

Gelman, A., \& Hill, J. (2006). Data analysis using regression and multilevel/hierarchical models. Cambridge: Cambridge University Press.

Goldhaber, D. \& Anthony, E. (2007). Can teacher quality be effectively assessed? Review of Economics and Statistics, 89(1), 134-150.

Goldhaber, D. D., \& Brewer, D. J. (2000). Does teacher certification matter? High school teacher certification status and student achievement, Educational Evaluation and Policy Analysis, 22, 129-145.

Gunes, F. (2014). Ogretim ilke ve yontemleri [Teaching principles and methods]. Ankara: Pegem Academy Publishing.

Johnson, B., \& Christensen, L. (2010). Educational research: Quantitative, qualitative, and mixed approaches ( $4^{\text {th }}$ ed.). Thousand Oaks, CA: Sage.

Jonassen, D. H. (1999). Designing constructivist learning environments. In C. M. Reigeluth (Ed.), Instructional design theories and models: A new paradigm of instructional theory (pp. 215-239). Mahwah, NJ: Lawrence Erlbaum Associates.

Koehler, M. J., \& Mishra, P. (2009). What is technological pedagogical content knowledge?, Contemporary Issues in Technology and Teacher Education, 9(1), 60-70.

Leung, W. L. A. (2008). Teacher concerns about curriculum reform: The case of project leaming, The Asia-Pacific Education Researcher 17(1), 75-97.

Liakopoulou, M. (2011). Teachers' pedagogical competence as a prerequisite for entering the profession, European Journal of Education, 46(4), 474-488.

MEB (2017). General competencies for teaching profession. Ankara, Turkey: Directorate General for Teacher Training and Development.

Mishra, P., \& Koehler, M. J. (2006). Technological pedagogical content knowledge: A framework for integrating technology in teacher knowledge, Teachers College Record, 108(6), 1017-1054.

OECD (2018). The future of education and skills. Paris: Organization for Economic Cooperation and Development Publishing.

OECD (2017). Teachers' pedagogical knowledge and the teaching profession. Paris: Organization for Economic Cooperation and Development Publishing.

OECD (2005) Education at a glance: OECD indicators 2006. Paris: Organization for Economic Cooperation and Development Publishing.

Phillips, D. C. (2003). Theories of teaching and learning. In R. Curren (Ed.), A companion to the philosophy of education (pp. 232-245). London: Blackwell Publishing.

Plourde, A. L., \& Alawiye, O. (2003). Constructivism and elementary preservice science teacher preparation: Knowledge to application, College Student Journal, 37(3), 334-342.

Richardson, V. (1996). The role of attitudes and beliefs in learning to teach. In J. Sikula (Ed.), Handbook of Research on Teacher Education (pp. 102-119). New York: Macmillan. 
Schunk, D. H. (2008). Learning theories: An educational perspective ( $5^{\text {th }}$ ed.). Upper Saddle River, New Jersey: Pearson Education, Inc.

Suciu, A. E., \& Mata, L. (2011). Pedagogical competences - The key to efficient education, International Online Journal of Educational Sciences, 3(2), 411-423.

Şahin, S., \& Yilmaz, H. (2016). A confirmatory factor analysis of the teaching and learning conceptions questionnaire (TLCQ), Journal of Instructional Psychology, 38(4), 1-7.

Senturk, C., \& Bas, G. (2018, April). Teaching-learning conceptions and effective lifelong learning in teachers: The mediating role of change tendencies. Paper presented at the meeting of the $27^{\text {th }}$ International Conference on Educational Sciences, Antalya, Turkey.

Tabachnick, B. G., \& Fidell, L. S. (2007). Using multivariate statistics ( $5^{\text {th }}$ ed.). New York: Pearson.

Wildman, T. M. (2008). Learning. In J. S. Neil and K. Rasmussen (Eds.), Encyclopedia of educational psychology (pp. 573-578). Los Angeles: Sage Publications.

Yildizli, H., Saban, A., \& Bastug, M. (2017). Teachers' teaching-learning concepts, teaching motivations and structural equation modeling on student achievement. In O. Demirel, \& S. Dincer (Eds.), Innovation and Quality in Educational Sciences (pp. 210-224). Ankara: Pegem Academy Publishing.

\section{Biographical notes:}

Asst. Prof. Dr. Cihad ŞENTÜRK works an assistant professor of curriculum and instruction at the Faculty of Education, Karamanoğlu Mehmetbey University, Karaman, Turkey. His research interests include curriculum and instruction, teaching-learning process, learning styles, alternative teaching-learning conceptions, primary education curriculums and mixed method research.

Asst. Prof. Dr. Gülçin ZEYBEK works an assistant professor at the Faculty of Education, Karamanoğlu Mehmetbey University, Karaman, Turkey. Her research interests include curriculum development, teaching methods, instructional technologies and mixed method research. 